\title{
CORONARY ARTERIAL FISTULA
}

\author{
BY \\ M. HONEY* \\ From the Department of Cardiology, St. Bartholomew's Hospital, London E.C.1
}

Congenital coronary artery fistula is a rare abnormality in which a branch of either coronary artery communicates with a cardiac chamber or with the pulmonary trunk. Recently Papaioannou and his colleagues (1962) reviewed 70 adequately documented cases, including one of their own; in 18 of these a branch of the right coronary artery entered the right ventricle. A further patient with this anomaly is described here, with observations on the problem of diagnosis and a possible surgical approach to the correction of the lesion.

\section{Case Report}

A man, aged 31 when he died, was first seen at this hospital in 1957 six years previously, when he was admitted for a hernia operation. He had been attending a physician elsewhere and was known to have congenital heart disease, which was then symptomless. At no time did he have a continuous murmur.

On examination, he had a collapsing pulse with capillary pulsation and a wide pulse pressure (blood pressure $150 / 45 \mathrm{~mm}$. $\mathrm{Hg}$ ). There was no cyanosis or clubbing and the venous pressure was normal. The heart was very large with hypertrophy of both ventricles. There was a very loud pan-systolic murmur, with thrill, maximal in the third intercostal space to the left of the sternum, an apical mid-diastolic murmur, and a soft blowing early-diastolic murmur down the left border of the sternum. The second sound was normally split.

The electrocardiogram showed left ventricular hypertrophy, without ST or T wave changes but with notching of the $R$ wave in leads I and V6 (Fig. 1a). On the chest radiograph there was enlargement of aorta and pulmonary trunk, and considerable pulmonary plethora. At cardiac catheterization, a large left-toright shunt at ventricular level was demonstrated (pulmonary/systemic flow ratio approximately 4:1), the pulmonary arterial pressure was slightly raised $(35 / 7 \mathrm{~mm}$. $\mathrm{Hg}$ above the sternal angle), and the pulmonary vascular resistance was normal. He was thought to have a ventricular septal defect with aortic regurgitation, but the discrepancy between the width of the pulse pressure and the inconspicuous early diastolic murmur was noted. Operation was not advised as he was then symptomless and as the presence of presumably free aortic reflux would have posed problems which at that time were insuperable.

He was not seen again until five years later when he returned with increasing effort dyspnœa and palpitation, and was found to have atrial fibrillation, with clinical and radiological evidence of pulmonary congestion. The signs were otherwise unchanged (phonocardiogram shown in Fig. 1c), but the electrocardiogram now showed evidence of right ventricular hypertrophy (Fig. 1b). The blood pressure was $170 / 30 \mathrm{~mm}$. Hg. In spite of treatment his condition deteriorated, and he was readmitted to hospital with right and left ventricular failure, pulmonary infarction, and secondary chest infection. He never improved sufficiently for further investigations to be undertaken, and he died in May 1963.

At necropsy (Dr. W. J. Hanbury) there was peripheral œedema, with pleural, pericardial, and peritoneal effusions, and chronic venous engorgement of the liver; the lungs were congested, œdematous, and hæmorrhagic. The heart was enormous $(1480 \mathrm{~g}$.) with dilatation and hypertrophy of both ventricles. The valves were normal apart from dilatation of the aortic and pulmonary valve rings; there were no septal defects, and the ductus arteriosus was closed. There was minimal atheroma of the aorta and left coronary artery which were otherwise normal. The right coronary artery arose from the right aortic sinus in the normal position,

* Present address: Brompton Hospital, London S.W.3. 


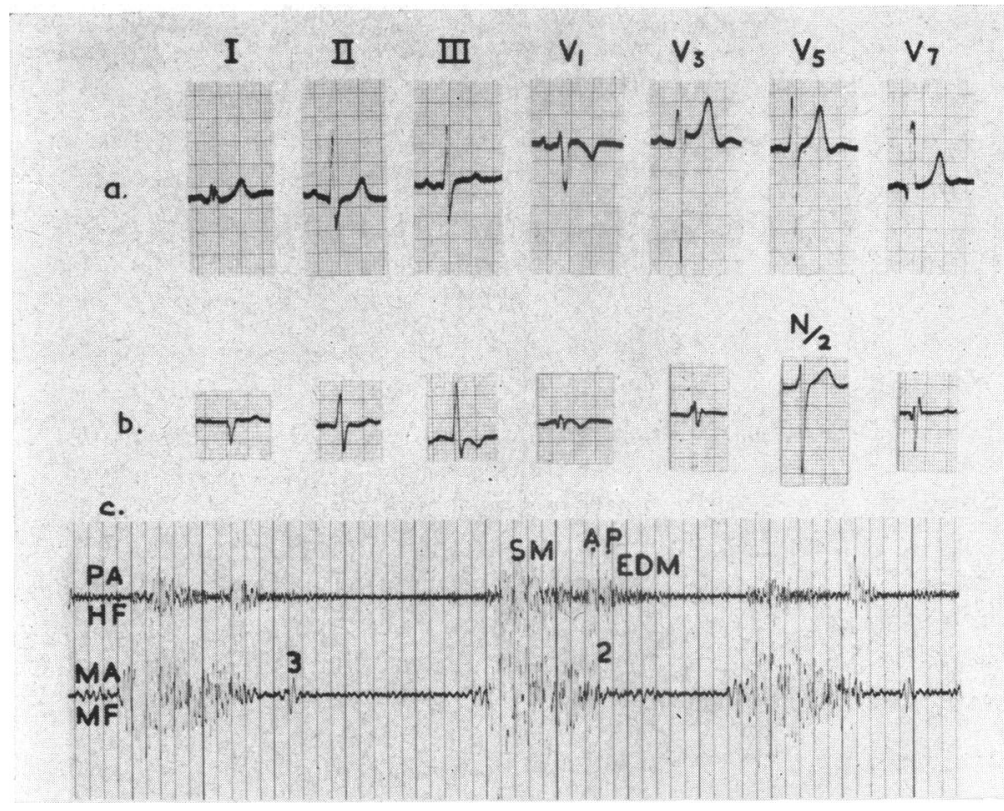

FIG. 1.-Electrocardiogram (a) five years before death and (b) during final illness. (c) Phonocardiogram PA/HF=pulmonary area, high frequency, and MA/MF = mitral area, medium frequency, recordings. $\mathbf{S M}=$ systolic murmur. 2, $\mathbf{A}, \mathbf{P}=$ second sound, aortic and pulmonary components. $\mathrm{EDM}=$ early diastolic murmur. $3=$ third sound.

but its orifice was $1.8 \mathrm{~cm}$. in diameter after fixation; it followed a normal course, but was greatly dilated (maximum circumference $8 \mathrm{~cm}$.); its wall was thickened, and there were intimal atheromatous plaques. It gave off normal-sized branches, but remained dilated until it reached a position corresponding to the posterior cusp of the tricuspid valve, where it turned inwards to communicate with the lumen of the right ventricle just below this cusp, through an orifice with a fibrous margin, $1.8 \mathrm{~cm}$. in diameter (Fig. 2).

\section{Discussion}

Congenital coronary arterial fistula is usually accompanied by a continuous murmur (Neill and Mounsey, 1958; Gasul et al., 1960; Neufeld et al., 1961; Papaioannou et al., 1962), and over the fistula the diastolic component is frequently louder than the systolic. Experience with this case shows that the diagnosis must be considered when a left-to-right shunt at ventricular level is found in a patient with a collapsing pulse and wide pulse pressure, even though the murmur is not continuous and the early diastolic murmur is relatively quiet. An aortogram will demonstrate the fistula, (Newcombe, Whitaker, and Keates, 1964) and is necessary when an apparent ventricular septal defect is accompanied by a wide pulse pressure or by an early diastolic or continuous murmur; it will distinguish a coronary arterial fistula from a ruptured aneurysm of a sinus of Valsalva, ventricular septal defect with aortic regurgitation, or ventricular septal defect with associated persistent ductus arteriosus.

The absence of a continuous murmur may have been due to the lack of tortuosity and large size of the right coronary artery and of the fistula itself; the shunt through the fistula was larger than in other reported cases. It is likely that there was free unimpeded flow through the fistula in diastole; this is supported by the low aortic diastolic pressure and the small gradient between the aorta (blood pressure $170 / 30 \mathrm{~mm} . \mathrm{Hg}$ ) and the right ventricle $(35 / 0 \mathrm{~mm} . \mathrm{Hg})$ in diastole. In systole, the diameter of the fistulous orifice into the ventricle, relative to that of the parent coronary artery, may 


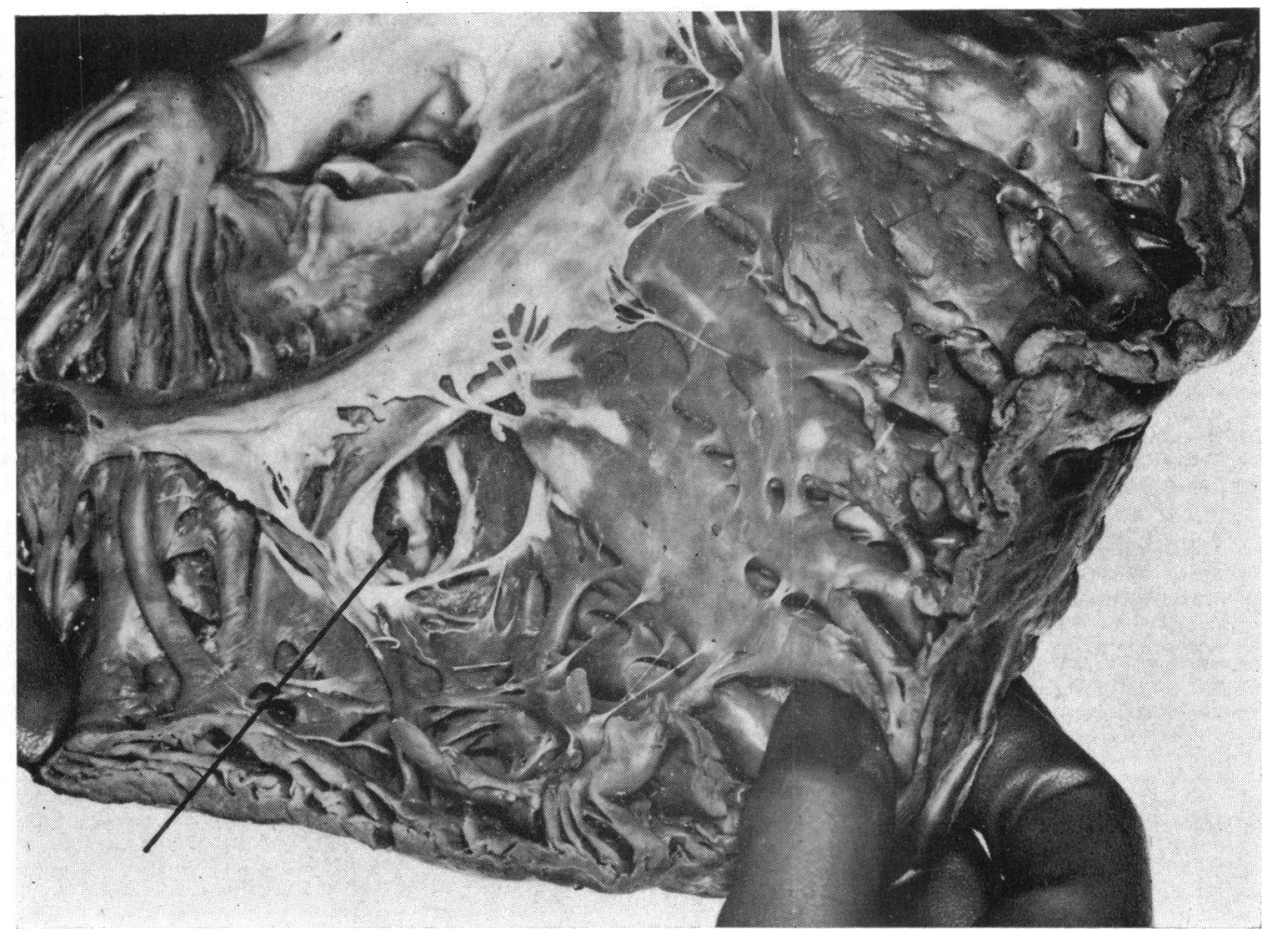

Fig. 2.-Photograph of the interior of the right atrium and ventricle. The orifice of the fistula (indicated by arrow) is seen below the posterior cusp of the tricuspid valve.

have been reduced by contraction of the surrounding myocardium, and increased resistance to flow resulted in a large systolic gradient between the aorta and the right ventricle with increased turbulence in the region of the fistula. The intense systolic murmur and quiet diastolic murmur can readily be explained on these assumptions. It is possible that a classical continuous murmur indicates a relatively small fistula with a large pressure gradient between the aorta and right ventricle throughout the cardiac cycle.

There have been several reports of successful surgical treatment by ligation of the coronary artery proximal and distal to the fistula, but Cooley and Ellis (1962) found that, even in children, this procedure may result in dangerous myocardial ischæmia or infarction. They suggested an alternative technique which they successfully employed in one of their cases; a row of mattress sutures is placed behind the coronary artery to obliterate the fistula, without interrupting the flow of blood through the parent vessel. In the patient reported here, the site of the fistula close to the atrio-ventricular groove at the back of the heart would have made access from outside the heart very difficult; however, using cardio-pulmonary bypass, exposure of the orifice by right ventriculotomy or by right atriotomy with detachment of the posterior leaflet of the tricuspid valve would have been good. Moreover, the margins of the fistula at its entry into the right ventricle were fibrous, and the insertion of sutures to bring together the margins of orifice under direct vision would have been straightforward, without endangering the parent coronary artery.

\section{Summary}

The patient reported here had a fistula between the right coronary artery and the right ventricle. The absence of a continuous murmur was very unusual and was probably related to the enormous size of the right coronary artery and of the fistula itself; the left-to-right shunt was exceptionally 
large and led to cardiac failure and death. The correct diagnosis was not made during life. The importance of aortography is stressed when a patient with an apparent ventricular septal defect has a wide pulse pressure, or a continuous or early diastolic murmur. The situation and fibrous margins of the orifice into the ventricle were such that closure could have been best accomplished under direct vision from within the ventricle, using cardio-pulmonary bypass.

I wish to thank Dr. G. W. Hayward, under whose care this patient was admitted, Dr. T. Parkinson for information about the earlier features of the illness, and Mr. A. Blesovsky for his observations on the surgical aspects of the case.

\section{References}

Cooley, D. A., and Ellis, P. R. (1962). Surgical considerations of coronary arterial fistula. Amer. J. Cardiol., 10, 467.

Gasul, B. M., Arcilla, R. A., Fell, E. H., Lynfield, J., Bicoff, J. P., and Luan, L. L. (1960). Congenital coronary arteriovenous fistula. Clinical, phonocardiographic, angiocardiographic, and hemodynamic studies in five patients. Pediatrics, $25,531$.

Neill, C., and Mounsey, P. (1958). Auscultation in patent ductus arteriosus; with a description of two fistulæ simulating patent ductus. Brit. Heart J., 20, 61.

Neufeld, H. N., Lester, R. G., Adams, P., Anderson, R. C., Lillehei, C. W., and Edwards, J. E. (1961). Congenital communication of a coronary artery with a cardiac chamber or the pulmonary trunk ("coronary artery fistula"). Circulation, 24, 171.

Newcombe, C. P., Whitaker, W., and Keates, P. G. (1964). Coronary arterio-venous fistulæ. Thorax, 19, 16.

Papaioannou, A., Agorogiannis, S., Nihoyanopoulos, J., and Lazzaridis, D. (1962). Congenital coronary artery fistula. Successful preoperative diagnosis and surgical correction. Amer. J. Cardiol., 10, 588. 